\title{
Especialização de jogadoras de handebol a partir dos discursos de treinadores
}

\section{Team handball players' specialization from coaches' speeches}

\section{Especialización de jugadoras de balonmano a partir de los discursos de entrenadores}

\author{
Santos, Walmir Romário dos; Menezes, Rafael Pombo \\ Universidade de São Paulo (USP), Escola de Educação Física e Esporte de Ribeirão Preto (EEFERP)
}

Financiamento: O presente trabalho foi realizado com apoio financeiro da Fundação de Amparo à Pesquisa do Estado de São Paulo (FAPESP, processo 2014/07967-7) e da Coordenação de Aperfeiçoamento de Pessoal de Nível Superior - Brasil (CAPES) - Código de Financiamento 001.

\section{RESUMO}

O objetivo deste trabalho foi analisar o processo de formação de jogadoras de handebol, a partir das opiniões de treinadores em relação às categorias e aos motivos considerados preponderantes para a especialização dessas. Para isso foram entrevistados seis treinadores, cujos depoimentos foram analisados com base no método do Discurso do Sujeito Coletivo. A partir dos discursos dos treinadores e da interlocução com diferentes autores aponta-se que, em uma perspectiva de longo prazo, a especialização das goleiras deve ocorrer preferencialmente na categoria sub-16, ao passo que a especialização das jogadoras de quadra na categoria sub-18. Os resultados indicam uma importante diretriz para a especialização de jogadoras de handebol em longo prazo, com diferentes prerrogativas para as goleiras e para as jogadoras de quadra, porém considerando ambientes de prática variada.

Palavras chave: Pedagogia do esporte. Especialização esportiva. Ensino-aprendizagem. Handebol.

\begin{abstract}
The aim of this work was to analyze the training process of handball players, based on the coaches' opinions regarding the categories and the reasons considered preponderant for their specialization. Six coaches were interviewed, whose speeches were analyzed based on the Collective Subject Discourse method. From the coaches' speeches and the comparisons with different authors, the specialization of the goalkeepers should preferably take place in the U-16 teams, while the specialization of court players in the U-18 teams. The results shows an important guideline for the specialization of handball players in a long term context, with different prerogatives for goalkeepers and court players, but considering environments with sampling practices.
\end{abstract}

Keywords: Sport pedagogy. Sport specialization. Teaching. Team handball. 


\section{Santos, W. R., Menezes, R. P.}

\section{RESUMEN}

El objetivo de este estudio fue analizar el proceso de formación de jugadoras de balonmano, desde los puntos de vista de los entrenadores sobre las categorías y las razones pertinentes para la especialización de éstas. Seis entrenadores fueron entrevistados, cuyas declaraciones fueran analizadas en base al método del Discurso del Sujeto Colectivo. A partir de los discursos de los entrenadores y el diálogo con los diferentes autores señala que, en una perspectiva a largo plazo, la especialización de las porteras deber ocurrir preferentemente en la categoría sub-16, mientras que la especialización de las jugadoras de campo en la categoría sub-18. Los resultados indican una directriz importante para la especialización de las jugadoras de balonmano en el largo plazo con diferentes justificaciones para las porteras y las jugadoras de campo, pero teniendo en cuenta los diversos entornos de la práctica.

Palabras clave: Pedagogía del deporte. Especialización deportiva. Enseñanza-aprendizaje. Balonmano.

\section{INTRODUCCIÓN}

As exigências para que as crianças atinjam altos níveis esportivos podem ignorar possíveis adequações de situações que garantam o acesso dessas a um processo de ensino-aprendizagem que promova o desenvolvimento de diferentes habilidades e capacidades a partir de uma formação de caráter generalista (Côtè, Baker \& Abernethy, 2007; Menezes, Marques \& Nunomura, 2014). A ocorrência de processos pedagógicos que visam alcançar ao êxito esportivo de crianças e jovens em curtos prazos e o estudo dos processos existentes vêm se tornando recorrentes na literatura (Côtè, Baker \& Abernethy, 2007; Acero Gómez, 2007; Menezes, Reis \& Tourinho Filho, 2015).

Considerando a perspectiva de formação em longo prazo, diferentes autores têm proposto modelos de desenvolvimento por intermédio do esporte. Um dos modelos é o proposto por Côtè, Baker \& Abernethy (2007), denominado Modelo de Desenvolvimento de Participação Esportiva (DMSP, do inglês Development Model of Sport Participation) que apresenta três carreiras esportivas distintas: a) práticas variadas na iniciação e continuidade em participações recreativas ao longo da vida (participação esportiva como conteúdo de lazer); b) práticas variadas com processo de especialização esportiva após a puberdade, visando à participação no alto rendimento ou lazer; c) especialização esportiva precoce.

No âmbito específico do handebol, Ehret, Spate, Schubert \& Roth (2002) apresentaram um modelo de formação em longo prazo considerando-se os aspectos a serem desenvolvidos em cada categoria (da sub-12 à sub-18). Os autores enfatizam que os jogadores devem passar por um processo de formação básica (até a categoria sub-12) e, na medida em que se aproximam da categoria sub-18, aumenta-se a especificidade de alguns aspectos ofensivos e defensivos. De maneira semelhante, Greco, Silva \& Greco (2012) apontam um modelo pautado nas mesmas categorias descritas por Ehret, Spate, Schubert \& Roth (2002), apresentando diferentes aspectos (ofensivos e defensivos) a serem abordados em cada uma dessas e possíveis procedimentos pedagógicos desde as categorias iniciais até alcançar a especialização dos jogadores.

Buscando encontrar o momento no qual deva ocorrer a especialização esportiva, Massa, Uezu, Böhme, Silva \& Knijnik (2010) analisaram os depoimentos de judocas convocados para os Jogos Olímpicos de Atenas (2004) e não apontaram uma idade considerada ideal para a especialização esportiva, uma vez que apenas um dos atletas entrevistados apresentou resultados expressivos precocemente.

Em relação ao voleibol, Guimarães, Mourão, Oliveira \& Santos (2009) entrevistaram nove treinadores para compreender as concepções destes sobre o treinamento e a formação de atletas do sexo feminino nas divisões iniciais da Federação de Voleibol do Estado do Rio de Janeiro. Os autores apontaram que a especialização deve ocorrer a partir da categoria sub-15, na qual há ênfase nas questões táticas individuais e coletivas. Milistetd et al. (2010) ao analisarem os discursos de dez treinadores de voleibol em âmbito nacional, apontaram que há a tendência de especializarem seus jogadores a partir dos 16 anos.

Em específico ao contexto do handebol, Canciglieri, Melari \& Pinheiro (2008) analisaram duas equipes de handebol de uma escola (11 meninos e 11 


\section{Discursos de treinadores e especialização de jogadoras de handebol}

meninas) do interior do Estado de São Paulo a partir de questionários com os jogadores e filmagens dos procedimentos pedagógicos adotados durante os treinamentos de uma equipe escolar do interior do Estado de São Paulo.

Considerando as diferenças entre os esportes, devido às suas especificidades, entende-se que os modelos que abordam o processo de formação esportiva diferem em relação ao estabelecimento de diretrizes para as faixas etárias e contextos de manifestação do esporte. Assim, apresenta-se como uma fértil perspectiva de investigação a opinião dos treinadores sobre a especialização de jogadores de handebol, principalmente envolvendo aspectos ao longo das categorias, pautando-se nas suas experiências profissionais.

Diante desse cenário, o objetivo desta pesquisa foi analisar o processo de formação de jogadoras de handebol, com atenção às categorias e aos motivos considerados preponderantes para a especialização dessas, a partir da ótica dos treinadores.

\section{MATERIAL Y MÉTODOS}

Desenho

Este estudo seguiu um desenho observacional nomotético (entrevista e posterior análise dos discursos de treinadores de handebol), pontual (cujo corte foi transversal, sem continuidade) e multidimensional (por admitir diversos aspectos para a especialização de jogadoras de handebol) (Anguera, Blanco-Villaseñor, Hernández-Mendo \& Losada, 2011).

\section{Tipo de pesquisa}

A opção pela abordagem qualitativa foi dada pela necessidade de buscar a compreensão e a atribuição de significados de um determinado grupo sobre dado assunto (Triviños, 1987), sem comparar grupos ou provar um dado modelo (Ato, López \& Benavente, 2013). A perspectiva dos participantes, assim como a reflexividade do pesquisador, são elementos fundamentais da pesquisa qualitativa (Flick, 2009) e, neste estudo, considera as opiniões dos treinadores sobre as categorias consideradas mais adequadas à especialização de jogadoras de handebol. A interpretação dos significados atribuídos pelas falas dos treinadores às questões específicas deste estudo não seguiu categorias pré-estabelecidas nem instrumentos observacionais de análise, mas às prerrogativas do método do Discurso do Sujeito Coletivo.

\section{Participantes}

Foram entrevistados seis treinadores de handebol (S1 a S6) considerando os seguintes critérios de inclusão: a) dirigir equipes femininas adultas de handebol; b) ter classificado a equipe entre as três primeiras colocadas nos Jogos Abertos do Interior do Estado de São Paulo; c) ter sido (ou ainda ser) treinador ou assistente de equipes de todas as categorias (sub-12, sub-14, sub-16, sub-18 e sub-21).

Neste estudo pretendeu-se compreender o discurso de um grupo de treinadores, selecionados de forma intencional, o que justifica seu número reduzido. Trata-se de uma análise qualitativa e não quantitativa das perspectivas dos treinadores que chegaram às finais de uma das principais competições do Estado de São Paulo (Jogos Abertos do Interior), que possui elevado nível técnico.

Todos os entrevistados são graduados em Educação Física há uma média de 17,5 $( \pm 9,1)$ anos, três são pós-graduados (lato sensu) em áreas correlatas e dirigem equipes de handebol há uma média de 18 $( \pm 5,9$ anos). Os treinadores assinaram um Termo de Consentimento Livre e Esclarecido (TCLE), aprovado previamente por um Comitê de Ética em Pesquisa institucional.

\section{Instrumento e procedimentos para entrevista}

Por se tratar de uma pesquisa de caráter qualitativo, a produção de informações referentes às opiniões e aos pensamentos expressos pelos treinadores foi realizada a partir de entrevista semiestruturada sobre a temática específica do estudo. Tal opção deu-se principalmente pela possibilidade de explorar de forma mais aprofundada (Marconi \& Lakatos, 2011; Thomas, Nelson \& Silverman, 2012) os aspectos mencionados pelos treinadores sobre a especialização de jogadoras de handebol.

As opiniões dos treinadores são importantes elementos para a compreensão do cenário da especialização das jogadoras de handebol, constituindo-se como uma forma de conhecimento que é compartilhada por indivíduos de uma mesma realidade, possuindo relevante representação daquele contexto social (Lefèvre \& Lefèvre, 2012). Este tipo de pesquisa parte de questionamentos referentes à pesquisa que, em seu decorrer, podem oferecer novas interrogativas na medida em que entrevistado 


\section{Santos, W. R., Menezes, R. P.}

apresenta sua visão sobre determinado tema (Triviños, 1987).

Como a intenção deste estudo foi de identificar as categorias consideradas adequadas para a especialização de jogadoras de handebol na opinião de treinadores, o instrumento de entrevista utilizado foi adaptado a partir da proposta de Menezes (2011), dividido em dois blocos: 1) dados pessoais, formação acadêmica e atuação profissional; 2) aspectos inerentes à especialização de jogadoras de handebol.

Desta forma, as questões norteadoras desta pesquisa se relacionaram com a categoria e os motivos para a especialização de jogadoras de handebol, assim constituídas: a) "qual idade você considera ideal para especializar o jogador em uma posição?”; b) “por que?"; c) "como você vê esse processo ao longo do tempo?". Pelo fato de se tratar de um pautado em entrevistas semiestruturadas, na medida em que novas questões foram surgindo houve a possibilidade de aprofundamento na temática em questão.

Os seguintes procedimentos foram adotados para a realização das entrevistas: 1) definição dos critérios para inclusão dos participantes; 2) contato inicial com o treinador; 3) agendamento da entrevista; 4) entrevista gravada na íntegra (por meio de aplicativo no Smartphone); 5) transcrição da entrevista (Triviños, 1987). Cada entrevista foi transcrita na íntegra no mesmo dia da sua realização, por considerar a latência do discurso (Oliver, Serovich \& Mason, 2005) e das anotações realizadas. Para a tabulação das entrevistas foi utilizado o Software Microsoft Word $^{\circledR}$ versão 2007.

As transcrições foram enviadas aos treinadores para possíveis ajustes e complementações, como forma de validar seu conteúdo e garantir a sua confiabilidade. Os arquivos de áudio contendo gravação das entrevistas foram armazenados em nuvem para proporcionar o acesso pelos pesquisadores a partir de qualquer dispositivo.

\section{Análise das entrevistas}

A tabulação e análise dos discursos foram realizadas a partir do método do Discurso do Sujeito Coletivo (DSC), que possibilita representar o pensamento de uma coletividade a partir dos seus depoimentos sobre uma determinada temática, reunindo as diversas respostas dos indivíduos, entretanto, que contenham conteúdos discursivos de sentido semelhante (Lefèvre \& Lefèvre, 2012).

$\mathrm{O}$ intuito foi de revelar os pensamentos dos treinadores sobre os principais aspectos inerentes ao processo de especialização de jogadoras de handebol, e não a busca por variáveis quantificáveis a priori. Assim sendo, o DSC pauta-se na Teoria das Representações Sociais descrita por Serge Moscovici, que "preocupa-se fundamentalmente com a interrelação entre sujeito e objeto e como se dá o processo de construção do conhecimento, ao mesmo tempo individual e coletivo" (CRUSOÉ, 2004, p.106).

$\mathrm{O}$ DSC pauta-se em três figuras metodológicas: a) as expressões-chave - ECH composta por transcrições literais de trechos contínuos ou descontínuos do discurso, que levam a revelação da essência do depoimento; b) as ideias centrais - IC descrição do sentido de um depoimento ou de um conjunto de depoimentos, revelando de maneira sintetizada e fidedigna o sentido desses, reduzindo a polissemia das ECH; c) e o DSC, que são o discursosíntese redigido na primeira pessoa do singular a partir das ECH que têm a mesma IC, cuja premissa também se refere à redução da polissemia dos discursos individuais (Lefèvre \& Lefèvre, 2012). Na Figura 1 está apresentado o fluxograma considerando desde a realização das entrevistas até a análise dos discursos (DSC). 


\section{Discursos de treinadores e especialização de jogadoras de handebol}

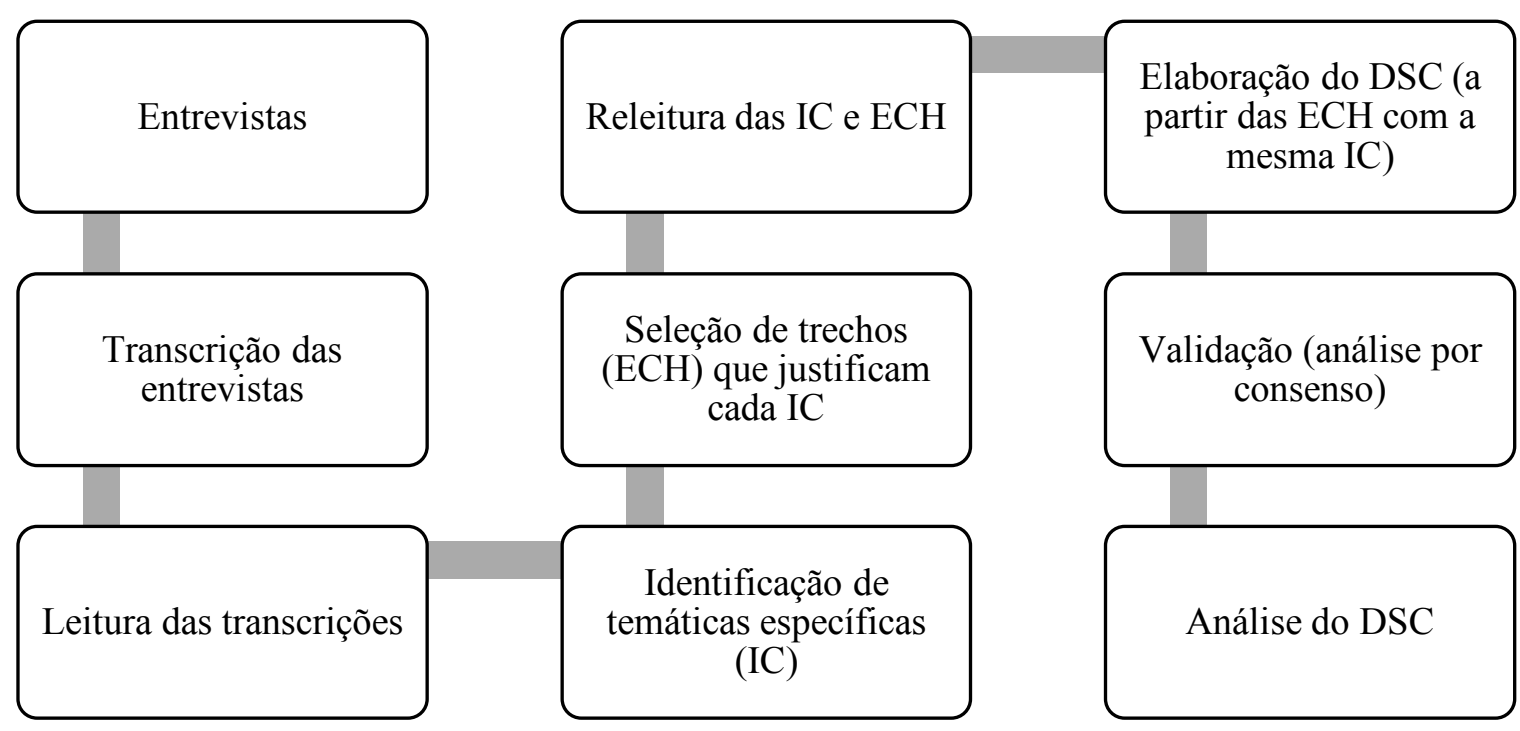

Figura 1: Fluxograma das etapas inerentes ao método do estudo

Destaca-se que as IC identificadas atendem aos princípios de mútua exclusividade e de exaustividade (Anguera \& Hernández-Mendo, 2013), em especial pelo fato de que cada ECH selecionada dos discursos é inerente a apenas uma IC e cada ECH que se referiu a alguma IC ainda não identificada permitiu a criação de outra categoria. Para garantir o controle da qualidade dos dados (especificamente da identificação das ECH, elaboração das IC e redação dos DSC) adotou-se como confiabilidade desses a concordância consensual (qualitativa) dos DSC elaborados simultaneamente por dois pesquisadores (Anguera \& Hernández-Mendo, 2013; Wright, Carling, Lawlor \& Collins, 2016; Modolo \& Menezes, 2019).

Assim sendo, o sistema de categorias adotado neste estudo partiu, inicialmente, das faixas etárias que constituem cada categoria no handebol, de acordo com as especificações da Confederação Brasileira de Handebol $^{1}$, perspectiva essa apontada por Anguera e Hernández-Mendo (2013). Esse sistema permitiu aos pesquisadores organizar e classificar as respostas dos treinadores de acordo com tais categorias, que cumprem critérios de exaustividade e mútua exclusividade (Anguera \& Hernández-Mendo, 2013;
Anguera, Portell, Chacón-Moscoso \& SanduveteChaves, 2018) dos depoimentos dos treinadores.

As seguintes categorias foram passíveis de apontamentos pelos treinadores: sub-12, sub-14, sub16, sub-18, sub-20 e adulta. Após as respostas dos treinadores, observou-se a necessidade de apresentar os resultados sob dois olhares: o primeiro considerando os aspectos relevantes para a formação e especialização das goleiras e o segundo considerando as jogadoras de quadra. Pelo fato de cada IC corresponder a uma categoria de observação elaborada a partir dos discursos dos treinadores, foi possível identificar três categorias principais. A primeira refere-se à especialização das goleiras na categoria sub-16; a segunda refere-se à especialização das jogadoras na categoria sub-18; enquanto a terceira é inerente à especialização após a categoria sub-18.

No Quadro 1 estão apresentados os agrupamentos das temáticas abordadas pelos treinadores, no qual a primeira coluna é destinada à categoria (e respectivo DSC), a segunda ao núcleo categorial que explica a rotulação do DSC (provenientes das diversas IC) e a terceira aos graus de abertura (características essenciais) apontadas nos discursos dos treinadores inerentes a cada DSC.

Quadro 1 - Critérios para agrupamento das opiniões dos treinadores em cada DSC, referentes às categorias, núcleo categorial e graus de abertura que influenciam suas opiniões para a especialização de jogadoras de handebol

\footnotetext{
${ }^{1}$ Disponível em: https://sge.cbhb.org.br/ uploads/orgaoAnexo/1CLy5yP9
} 3EVIFedRx3eujzX xn2cSJT.pdf 
Santos, W. R., Menezes, R. P.

\begin{tabular}{|c|c|c|}
\hline Categoria & Núcleo categorial & Grau de abertura (características essenciais) \\
\hline Sub-16 (DSC1) & - Goleiras & $\begin{array}{l}\text { - Técnica específica } \\
\text { - Tática específica } \\
\text { - Processo de longo prazo }\end{array}$ \\
\hline Sub-18 (DSC2) & $\begin{array}{l}\text { - Jogadoras de quadra } \\
\text { - Categoria sub-18 }\end{array}$ & $\begin{array}{l}\text { - Experiências prévias } \\
\text { - Especializar em dois ou mais postos } \\
\text { - Maturação }\end{array}$ \\
\hline $\begin{array}{c}\text { Após a categoria sub-18 } \\
\text { (DSC3) }\end{array}$ & $\begin{array}{l}\text { - Jogadoras de quadra } \\
\text { - Categorias sub-20 e adulta }\end{array}$ & $\begin{array}{l}\text { - Apenas na categoria adulta } \\
\text { - Prazo longo para especializar }\end{array}$ \\
\hline
\end{tabular}

Foi possível recorrer aos discursos originais como forma de verificação de dúvidas pelo fato de haver o registro dos áudios e das transcrições na íntegra. Cada IC sintetiza, portanto, a temática central abordada por cada DSC, assim como proposto em outros estudos com treinadores de handebol (Menezes, Marques \& Nunomura, 2015, 2017).

Na seção "Resultados" serão apresentados os DSC em dois sub-temas: especialização das goleiras e especialização das jogadoras de quadra. Em cada DSC as origens das falas (treinadores) estão apresentadas de maneira sobrescrita. Em diversas circunstâncias os DSC apontam substantivos masculinos (como "jogadores", por exemplo), o que foi compreendido como linguagem coloquial e, desta forma, a discussão pautou-se em considerar o contexto das equipes femininas por entender que os treinadores se referiam ao contexto de suas equipes. Destaca-se que o objetivo não foi a busca por determinar uma categoria para a especialização das jogadoras, mas revelar os pensamentos dos treinadores sobre os principais argumentos que influenciam esse processo.

\section{RESULTADOS}

Os resultados mostraram três perspectivas para a especialização de jogadoras de handebol. A primeira delas - DSC1 - representa um posicionamento unânime dos treinadores sobre a especialização das goleiras, os quais apontam que deva ocorrer na categoria sub-16. As demais perspectivas sugerem que a especialização das jogadoras nos postos específicos de quadra deva ocorrer na categoria sub-18 (representada pelo DSC2, cuja opinião foi compartilhada por cinco treinadores) ou após essa categoria (abordada no DSC3, com opinião compartilhada por dois treinadores). Os DSC estão apresentados no Quadro 2.

Quadro 2: IC e DSC referentes às categorias mencionadas para a especialização de jogadoras de handebol

IC-1: Especializar as goleiras na categoria sub-16 (S1, S2, S3, S4, S5, S6)

DSC1: No sub-12 ele tem que brincar e aprender a se posicionar em relação ao jogador, tem que tirar aquela visão do futebol de que tomou gol é frango; explicar que ele vai tomar milhões de gols e fazer ele gostar ${ }^{\mathrm{S} 4}$. No sub-14 começar com os gestos técnicos específicos para aprimorá-los no sub-16 ${ }^{\mathrm{S}}$. Então com 13 anos tem dia que vai treinar só com as goleiras, pois requer uma situação diferenciada, as habilidades, o tempo de reação, a flexibilidade, o trabalhinho de agilidade debaixo das traves são diferentes ${ }^{\mathrm{S} 1}$; já vai ser apresentado os gestos técnicos de goleiro ${ }^{\mathrm{S} 4}$. No sub-16 ${ }^{\mathrm{S} 2, \mathrm{~S} 3, \mathrm{~S} 6}$ já tem uma noção pra começar ${ }^{\mathrm{S} 3}$, porque o trabalho de goleiro é mais ágil ${ }^{\mathrm{S} 6}$, vai para o gol e não treina mais na linha; o goleiro é ele quem decide, você pode até escolher um cara, mas se ele falar que não vai, não adianta ${ }^{\mathrm{S} 5}$. Acho que, apesar de alguns começarem antes, deveria a partir dos 16 aprofundar o trabalho do goleiro ${ }^{\mathrm{S} 6}$, daí já começa a ensinar o que o goleiro tem que fazer, pra chegar no sub-18 e saber jogar legal e no adulto competir de igual pra igual. No sub-18 o goleiro não tem como passar nas outras posições, ele passa lá mais para brincar; já deve estar pronto ${ }^{\mathrm{SS}}$.

IC-2: Especialização das jogadoras de quadra na categoria sub-18 (S1, S2, S3, S4, S5)

DSC2: A especialização deve acontecer no sub-1 $8^{\mathrm{S} 1, \mathrm{~S} 2, \mathrm{~S} 3, \mathrm{~S} 5}$, daí para cima tem que ser especializado ${ }^{\mathrm{S} 3, \mathrm{~S} 5}$, mesmo assim a gente ainda tem atleta que não tem um posto específico pela carência de não ter recurso para ter um atleta ou dois atletas em cada posição ${ }^{\mathrm{S} 3}$. No sub-16 já teve uma bagagem de todas as posições no sub-12, no sub-14 e no sub-16 já tem uma maturação física e dá pra prever como ele vai se formar. A maioria é nessa época que acaba o estirão, daí você já tem noção do porte físico, da questão técnica e consegue direcionar pra onde ele deve ir ${ }^{\mathrm{S} 4}$. Mas é bom passar por todas as posições, porque está melhorando a coordenação deles ${ }^{\mathrm{S} 3}$. Se a menina precisar sair da armação e ir pra ponta ela vai e vice-versa; eu fecharia mesmo esse posto com quase 17 na nossa realidade hoje, e considero ideal 13-14 anos para 


\title{
Discursos de treinadores e especialização de jogadoras de handebol
}

\begin{abstract}
investir mais na especificidade do posto ${ }^{\mathrm{S} 1}$. Do sub-18 para cima você tem que falar assim: 'agora você vai fazer isso, você tem que saber isso' ${ }^{\text {'5 }}$; antes disso não tem como definir o que o jogador vai ser, ele pode deixar claro algumas coisas, por exemplo: você pega um grandão lá e esse cara dá três passos e bate bem de fora, ele vai ser armador... Não! Ele pode ser pivô, goleiro ${ }^{\mathrm{S} 5}$... Acho que o sub-18 é uma idade interessante porque ele já fez todas as coisas ${ }^{\mathrm{S} 4}$, mas especializaria em duas ou três posições ${ }^{\mathrm{S} 1, \mathrm{~S} 2, \mathrm{~S} 5}$. Duas com certeza, mas acho que tem uma terceira que tenha habilidade e que tem que ser conduzida também no sub-18 a utilizar essa habilidade em algum momento, ou o técnico utilizar essa habilidade dele em algum momento de jogo ${ }^{\mathrm{S} 2 \mathrm{~S} 5}$.
\end{abstract}

\section{IC-3: Especialização das jogadoras de quadra após a categoria sub-18 (S2, S6)}

DSC3: Se for especializar em uma posição seria só no adulto, e olhe lá! Por que como você vai especializar uma armadora, sendo que de repente ela tem mais habilidade do que a outra armadora? ${ }^{\mathrm{S} 2}$. A partir dos 18 acho que ele tá capacitado, porque se trabalhou em todas as categorias voltado com esse conhecimento ${ }^{\mathrm{S} 6}$.

Nesse contexto destaca-se o posicionamento do S2 que, embora esteja presente no DSC2 e no DSC3, aponta uma perspectiva de especialização em dois ou mais postos específicos na categoria sub-18 para então, se houver necessidade, especializar em um desses na categoria adulta (o que parece uma condição remota ao sujeito no DSC3).

\section{DISCUSSÃO}

No DSC1 foi possível identificar o percurso compreendido pelos treinadores para a especialização das goleiras, partindo da categoria sub-12 até alcançar a especialização no final da categoria sub-16. Destacam-se nesse posicionamento dois aspectos: a) o fato de considerar esse percurso como um processo de longo prazo; e b) o fato de estar em consonância com uma das carreiras (práticas variadas com processo de especialização esportiva após a puberdade) apresentadas por Côtè, Baker \& Abernethy (2007), preconizando o oferecimento de experiências diversificadas nas etapas iniciais e aumentando a especificidade dos treinamentos ao longo do tempo, até atingir a especialização.

As goleiras devem estar preparadas para defender utilizando diferentes segmentos corporais, o que é influenciado pela trajetória da bola, pelas distâncias do arremesso em relação ao gol e pelas posições de quadra. A atuação da goleira depende de uma formação inicialmente generalista, que a possibilite observar o contexto do jogo para planejar a sua tomada de decisão para que, ao longo do tempo, seja possível aprimorar os elementos técnicos e técnico-táticos específicos do posto. As características temporais e espaciais do posicionamento dos jogadores são essenciais para que compreendam as relações de cooperação e oposição (Corrêa, Davids,
Silva, Danardi \& Tani, 2014) em um ambiente técnico-tático complexo (Menezes, 2012). Tal compreensão perpassa pela identificação de padrões que influenciam e determinam o funcionamento do jogo ao longo do processo de ensino (Sainz de Baranda, Ortega, Palao \& 2008; Corrêa, Davids, Silva, Danardi \& Tani, 2014; Menezes, 2018).

No Estado de São Paulo as Ligas e a Federação Paulista de Handebol organizam competições que iniciam-se geralmente na categoria sub-12, que podem representar o início da vida competitiva e/ou esportiva de muitos jovens. No DSC 1 os treinadores apontam que a categoria sub-12 marca o início do processo de treinamento das goleiras, na qual as vivências desse posto específico ocorrem de forma estendida a todas as jogadoras e, ainda, enfatizando aspectos gerais relacionados ao seu posicionamento.

Por se tratar de um momento de intensas mudanças metabólicas e morfológicas (Malina, Bouchard \& Bar-Or, 2009) é necessário iniciar a jovem esportista em uma formação generalista (Ehret, Spate, Schubert \& Roth, 2002). Assim, as atividades propostas nessa etapa devem ter como característica o prazer pela prática, concordando com as premissas apontadas por Côtè, Baker \& Abernethy (2007).

Acero Gómez (2007) aborda a formação de goleiros de handebol em duas etapas: a) iniciação, com exercícios enfatizando equilíbrio, reação e sentido do passe (por serem consideradas essenciais para o seu êxito); e b) aperfeiçoamento, com maior ênfase nas variáveis da iniciação associadas à coordenação e à técnica no gol. Greco, Silva \& Greco (2012) apontam que durante a etapa de aperfeiçoamento os goleiros devem ser estimulados à colaboração com os jogadores de quadra, organizando-os e orientando a defesa em relação ao seu posicionamento, trabalhando com os bloqueios defensivos e com o marcador das 


\section{Santos, W. R., Menezes, R. P.}

pontas. A técnica também deve ser aprimorada, como a qualidade dos passes (Acero Gómez, 2007), a posição de base do goleiro, seus deslocamentos e fintas. Também devem ser enfatizadas variáveis coordenativas, de força, de resistência e de agilidade, respeitando as características biotipológicas, psicológicas e físicas dos jovens (Greco \& Benda, 2002).

Observou-se no DSC1 que na categoria sub14 é importante o desenvolvimento dos elementos específicos do posto de goleira que servirão como base para as demais categorias. Nas categorias anteriores à sub-16 devem ser priorizados, portanto, aspectos que possibilitem às goleiras perceber o ambiente do jogo, tomar decisões adequadas aos cenários apresentados pelo atacante em posse da bola (Latiskevits, 1991), vivenciar diferentes postos específicos ofensivos e defensivos (Antón Gárcia, 2000; Antón García, 2000; Ehret, Spate, Schubert \& Roth 2002) e diferentes posicionamentos e deslocamentos (Antón Gárcia, 2000). Tais prerrogativas apontam para uma formação generalista, cujas múltiplas vivências em diferentes postos específicos auxiliam na formação da goleira em longo prazo, assim como apontado pelos treinadores no DSC1.

Ehret, Spate, Schubert \& Roth (2002) apontam que por volta dos 11-12 anos o treinador deve encontrar um jogador que se responsabilize pelo posto específico de goleiro, iniciando aos 13-14 anos o processo de treinamento da técnica básica de goleiro. Dessa maneira, os treinos específicos podem ser iniciados na categoria sub-14 (Ehret, Spate, Schubert \& Roth, 2002; Greco, Silva \& Greco, 2012) e o aprimoramento dos gestos técnicos pode ser realizado na categoria sub-16, momento no qual abordam-se questões referentes à especialização (Antón García, 2000).

No DSC1 também é externada a preocupação com as amplas vivências na categoria sub-12 e o início do treinamento específico na categoria sub-14, ou seja, preconiza-se que as goleiras devem possuir experiências variadas ao longo de sua formação esportiva sem necessariamente desenvolver de forma especializada os elementos técnicos e técnico-táticos até as categorias sub-12 e sub-14. Antón García (2000) aponta que a categoria sub-14 deve ser a responsável pelo desenvolvimento generalista do goleiro por meio de vivências básicas da posição, podendo ser o momento ideal para a ênfase em posicionamento e deslocamentos (fundamentais para o êxito na modalidade). Entretanto o autor considera que a especialização deva ocorrer na categoria sub-16, opinião compartilhada pelo DSC1, sugerindo que o desenvolvimento dos aspectos especializados das goleiras deva ser realizado na categoria sub-16. Os treinadores justificam essa escolha pautada em parâmetros como maior agilidade nessa idade quando comparada com as categorias anteriores (assim como apontado por Menezes, Reis \& Tourinho Filho, 2015) e a pré-disposição (ou identificação) em relação ao posto específico (corroborando a opinião de Ehret, Spate, Schubert \& Roth, 2002).

Espera-se que a goleira desenvolva grande parte do seu repertório de tomada de decisão até a categoria sub-16, para que possa aprimorá-las na categoria sub-18 e nas subsequentes, devido às maiores demandas técnico-táticas e à exigência de uma maior eficácia na medida em que se aproxima do alto nível. Esse posicionamento dos entrevistados corrobora Antón García (2000) e Greco, Silva \& Greco (2012), que afirmam que se o processo de treinamento dos goleiros for realizado de maneira adequada em categorias como a sub-14 e a sub-16, esses terão autonomia para colocar em prática suas habilidades e conhecimentos na categoria sub-18. Considerando o panorama relatado no DSC1, entendese que há concordância com o fato de iniciar treinos específicos na categoria sub-14, tendo a categoria sub16 como o marco para a especialização.

Quando a temática envolveu a especialização das jogadoras de quadra foram elaborados dois DSC: DSC2 - que preconiza a especialização na categoria sub-18 (opinião compartilhada por $\mathrm{S} 1, \mathrm{~S} 2, \mathrm{~S} 3, \mathrm{~S} 4$ e S5) - e DSC3 - que aponta a especialização após a categoria sub-18 (opinião compartilhada por S2 e S6).

O DSC2 aponta diferentes aspectos que devem ser considerados para a especialização das jogadoras de quadra, destacando a melhora da coordenação, os aspectos maturacionais e, de maneira implícita, o desenvolvimento do repertório de tomada de decisão. Os treinadores destacam a importância de o jogador conseguir jogar em diferentes postos específicos, atendendo às mudanças no complexo cenário do jogo (Menezes, 2012).

Embora seja considerada uma faixa etária diferente para a especialização quando comparado com o DSC1, alguns dos argumentos são semelhantes, como as experiências variadas e a formação das jogadoras em longo prazo culminando na especialização na categoria sub-18. Tal prerrogativa 


\section{Discursos de treinadores e especialização de jogadoras de handebol}

difere do modelo proposto por Côtè, Baker \& Abernethy (2007) em relação à faixa etária para a especialização, mas concorda em preconizar ao longo das categorias estímulos direcionados cada vez mais em busca da especialização, porém partindo-se de uma base de amplas experiências (em especial quando mencionam as duas carreiras que são contrapostas à ideia da especialização esportiva precoce).

No DSC2 os treinadores apontam que tal especialização deva ocorrer na categoria sub-18, todavia devem ser contemplados ao menos dois postos específicos. A diferença entre o DSC2 e o DSC3 reside no fato de que se considera a especialização em apenas um posto no DSC3, ainda de maneira condicional, pois considera que talvez não seja viável tal especialização. A opinião apresentada pelo S2, embora presente nos dois discursos, aponta uma perspectiva de especialização em dois ou mais postos específicos na categoria sub-18 para então, se houver necessidade, especializar em um na categoria adulta (o que parece uma condição remota ao sujeito no DSC3).

Os argumentos para a especialização esportiva na categoria sub-18 vão ao encontro dos preceitos apontados por Menezes (2010), pois uma das maiores dificuldades enfrentadas pelos treinadores é o início tardio dos jogadores no handebol, comumente a partir da categoria sub-16 ou sub-18. Alguns fatores podem estar associados a essa questão: a ausência do handebol como parte do conteúdo escolar em algumas instituições (como mini handebol ou variações do próprio jogo); a rara veiculação do handebol em canais abertos de televisão; e a possível falta de conhecimento sobre as regras e a dinâmica da modalidade por parte dos profissionais de Educação Física envolvidos no âmbito escolar (Menezes, 2010).

Os achados no DSC2 e no DSC3 vão ao encontro dos apontamentos de Hernandes, Ferronato \& Fraga (2015), de que na categoria sub-18 um dos enfoques deve ser o desenvolvimento da capacidade de jogo diante de diferentes posicionamentos defensivos e ofensivos. A partir das perspectivas do DSC2 e do DSC 3 o desenvolvimento da capacidade de jogo referida pelas autoras citadas somente será possível após as vivências ao longo do processo de ensino-aprendizagem, com vistas à formação de amplo repertório motor e de tomada de decisão.

Ehret, Spate, Schubert \& Roth (2002) apontam a faixa etária de 15 e 16 anos como adequada para especializar jogadores de handebol, porém atentando à formação do jogador com caráter generalista. O posicionamento expresso no DSC2 destaca a importância dessa formação generalista, visto que a carência de jogadores por postos específicos em algumas equipes gera vantagens a aqueles que atuam em dois ou mais postos. Essa característica é reforçada ao longo do processo de ensino-aprendizagem a partir do desenvolvimento da capacidade de jogo sem obrigações táticas específicas (como sugerido para a categoria sub-14 por Hernandes, Ferronato \& Fraga (2015).

Silva, Fonseca \& Barreiros (2019) apontam que durante a fase de especialização os treinadores devem motivar e encorajar a tomada de decisão. Os atletas devem se desenvolver mediante um cenário complexo e se tornarem aptos para se adequarem às imprevisibilidades que podem surgir no contexto esportivo.

Ao mencionar a especialização em dois ou três postos específicos, o DSC2 vai ao encontro das prerrogativas assinaladas por Ehret, Spate, Schubert \& Roth (2002) e Greco, Silva \& Greco (2012), que apontam a categoria sub-16 como a mais indicada para abordar as especificidades dos postos, porém com os jogadores atuando em todos esses postos específicos. A tática individual deve ser estimulada na universalidade das posições, caráter essencial para o desenvolvimento da capacidade de jogo (Ehret, Spate, Schubert \& Roth, 2002).

Para que a jogadora possa ser especializada em diferentes posições é importante que o processo de ensino em longo prazo seja pautado na variabilidade de estímulos. Na proposta de Côtè, Baker \& Abernethy (2007) para a carreira referente às práticas variadas com processo de especialização esportiva após a puberdade, são descritas três etapas: a) diversificação (até aproximadamente 12 anos de idade), caracterizada pelo envolvimento do praticante com o máximo de experiências esportivas possíveis buscando, sobretudo, o gosto pela prática; b) especialização (abrange a faixa etária entre 13 e 15 anos, aproximadamente), caracterizada pelo aumento da especificidade em relação a um esporte, entretanto com flexibilidade para a prática de outros esportes; c) de investimento (iniciada com aproximadamente 1516 anos), cujo foco volta-se para o treinamento regular e sistematizado em um esporte, com o aumento na participação competitiva e a busca por resultados.

Considerando o modelo dos autores supramencionados é possível identificar semelhanças com as prerrogativas apresentadas no DSC2, 


\section{Santos, W. R., Menezes, R. P.}

principalmente relacionadas às amplas vivências (embora num contexto específico do handebol, sem mencionar outros esportes - que não se constituem como ponto central desta pesquisa).

Canciglieri, Melari \& Pinheiro (2008) constataram que a idade inicial dos jogadores nos treinamentos escolares da amostra analisada foi entre 10 a 12 anos, tecendo críticas ao volume e à intensidade dos treinamentos que, na visão desses, estavam intimamente relacionados a um ambiente de especialização precoce. Diante dos achados do nosso estudo e pautando-se nas diretrizes mencionadas por diferentes autores consultados, entende-se que tais práticas não devem constituir a tônica central para a faixa etária apresentada, na qual a preocupação deva estar voltada ao oferecimento de vivências amplas em todos os postos específicos, conforme discutido anteriormente.

Greco \& Benda (2002) sugerem que entre as categorias sub-12 e sub-16 já deva ocorrer a iniciação aos treinamentos táticos do handebol, aos posicionamentos e à percepção dos jogadores, ao passo que na categoria sub-18 deva-se intensificar as técnicas em situações de jogo. Entende-se que os apontamentos dos autores foram ecoados nos depoimentos dos treinadores (principalmente no DSC1 e DSC2). Considerando o processo de ensino em longo prazo, os treinadores também manifestaram a preocupação com a especialização na categoria sub18 , apoiando-se no fato de que as amplas vivências são necessárias ao longo desse processo, possibilitando às jogadoras o contato com diferentes elementos técnicos e táticos em diferentes contextos do jogo. Acredita-se, a partir dos resultados desta pesquisa, que o processo de ensino deva ser pautado no desenvolvimento integral da jogadora preferencialmente em ambientes com vivências ricas e variadas, que podem ser garantidas a partir de métodos de ensino ativos, como o situacional e o global-funcional (Menezes, Marques \& Nunomura, 2014; Menezes; Reis \& Tourinho Filho, 2015).

Em estudo com 71 treinadores de handebol que atuaram na temporada 2006-07 de competições organizadas pela Federação Portuguesa de Handebol, Massuça \& Fragoso (2010) aplicaram um questionário para identificar as variáveis que os treinadores acreditavam ser essenciais para o sucesso (acesso ao alto rendimento) do jogador no handebol (sexo masculino), constatando não há apenas um perfil determinante, mas vários. Os resultados encontrados nesta pesquisa corroboram a multiplicidade de opiniões dos autores supracitados, pois a partir do pressuposto de que há diferentes perfis para o jogador de handebol, entende-se a ideia da formação generalista que possibilite a atuação em diferentes postos específicos, mesmo após a etapa de especialização.

Embora também não constituam a tônica central desta pesquisa, os treinadores mencionaram a influência dos aspectos maturacionais para a especialização das jogadoras de quadra (DSC2), o que também foi citado como um perfil de possível sucesso por Massuça \& Fragoso (2010). As características antropométricas como a estatura, cujo pico é alcançado por volta dos 16 anos nas meninas e dos 18 nos meninos, devem ser levados em consideração por pela sua estabilização por volta da categoria sub-18, coincidindo com o possível final da maturação sexual (Malina, Bouchard \& Bar-Or, 2009). Embora o crescimento cesse próximo ou na categoria sub-18, este deve ser considerado quando da elaboração das sessões de treinamento para a melhoria, inclusive, das capacidades motoras (Menezes, Reis \& Tourinho Filho, 2015). Todavia, é necessário relatar que embora os aspectos antropométricos sejam importantes no processo, a experimentação permitirá ao esportista um estado de foco energizado e o envolvimento ativo independente de sua classificação maturacional (Carraça, Serpa, Palmi \& Rosado, 2018).

Após a análise dos discursos foram identificados aspectos considerados importantes pelos treinadores e por diferentes pesquisadores no sentido de promover um caminho até a especialização de jogadoras de handebol. Não obstante, há que considerar a observância das seguintes particularidades: a) as goleiras são especializadas em uma categoria anterior às jogadoras de quadra, o que é justificado pela especificidade do posto; b) as jogadoras de quadra devem passar por todos os postos específicos, o que lhes garantirá repertórios motor e cognitivo para tomar suas decisões em diferentes situações; c) não há consenso sobre a especialização em apenas um posto específico para as jogadoras de quadra, o que sustenta a característica de um comportamento técnico-tático flexível das jogadoras, pautado nas transformações dos sistemas ofensivos; d) também não há um consenso sobre a necessidade de especializar em apenas um posto, o que seria uma possível condição (remota, para um dos entrevistados) apenas na categoria adulta; e) alguns dos 


\section{Discursos de treinadores e especialização de jogadoras de handebol}

apontamentos dos treinadores encontram respaldo nos autores investigados, conferindo coerência ao processo de ensino até a fase de especialização.

$\mathrm{Na}$ Figura 2 está apresentado um esquemasíntese dos aspectos que consideramos interessantes ao longo do processo de especialização das jogadoras de handebol, com possíveis balizadores para cada categoria.

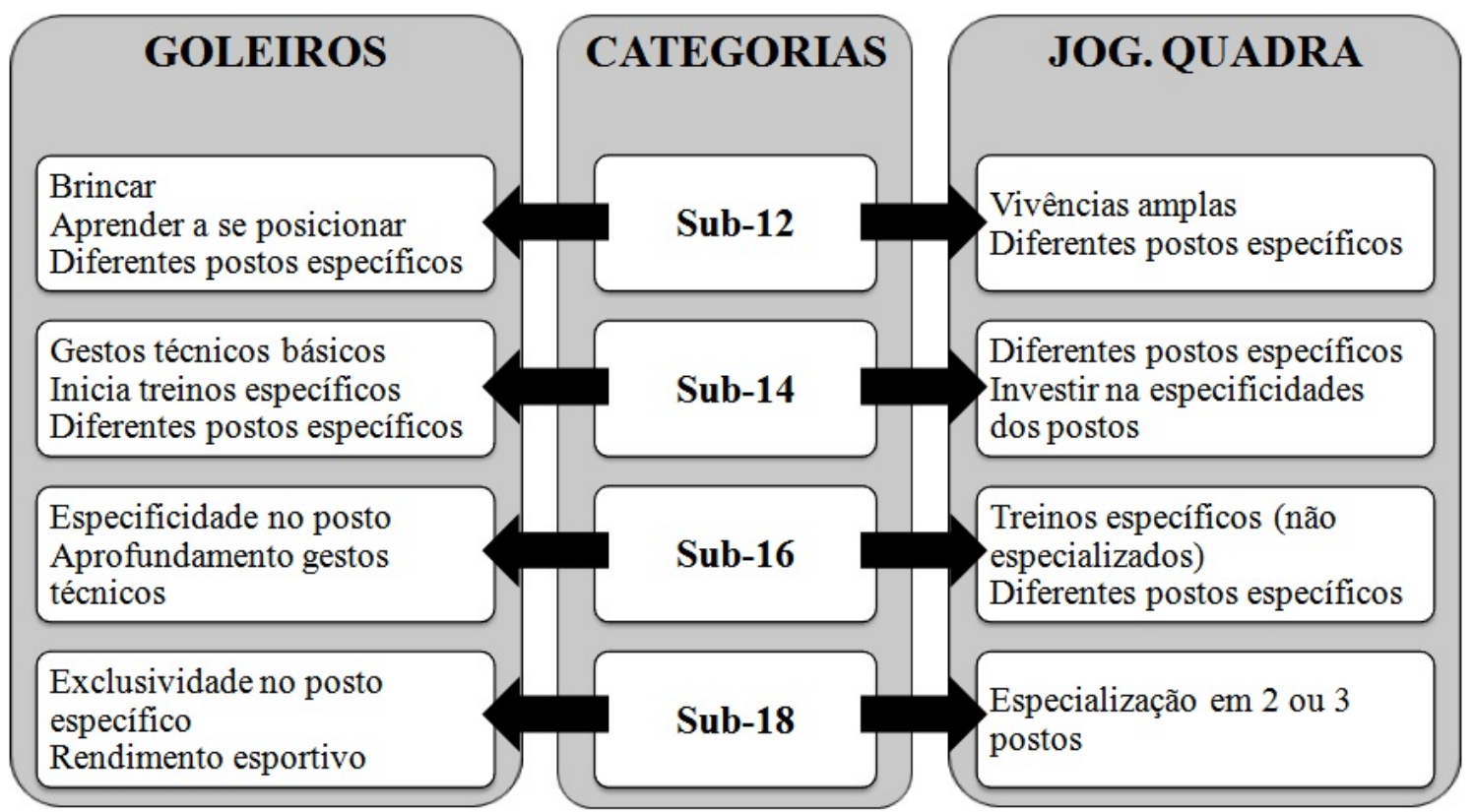

Figura 2: Aspectos relacionados à especialização de goleiras e jogadoras de quadra ao longo das categorias

Enfatiza-se que para as goleiras as habilidades e competências inerentes ao posto específico são apresentadas paulatinamente, desde a primeira experiência (na qual requerer-se-á a aprendizagem do posicionamento), perpassando pela aprendizagem dos gestos técnicos básicos (em treinamentos mais específicos) e da interpretação do cenário do jogo, para então investir-se na especialização (buscando o desenvolvimento de elementos técnicos e táticos). Por outro lado, inicia-se o processo de especialização na categoria anterior às jogadoras de quadra.

Já para as jogadoras de quadra os treinadores apresentam um processo de formação mais longo do que o de goleiras, pois a especialização nos postos específicos tem como referência a categoria sub-18. Para esses, as vivências variadas e a formação em longo prazo são essenciais, pois a compreensão dos elementos técnico-táticos é necessária para corresponder às demandas do cenário do jogo, justificando o fato das jogadoras possuírem recursos para atuarem em dois ou mais postos específicos.

Esse aspecto demanda conhecimento do treinador sobre a sistematização do processo de formação esportiva para que o desenvolvimento de competências dos jogadores possa atingir os patamares almejados, bem como possa ser contínuo de uma temporada a outra (Morelló Tomás, Vert Boyer \& Navarro Barquero, 2018). A partir da perspectiva de desenvolvimento em longo prazo, espera-se evitar uma seleção precoce dos jogadores para determinados postos específicos, pautando-se na necessidade de alcançar resultados competitivos expressivos em etapas que podem ir de encontro aos objetivos desses (Barreiros, Côté \& Fonseca, 2013), desmotivá-los e levar ao abandono do handebol.

A identificação das categorias consideradas adequadas para a especialização, assim como as razões pelas quais os treinadores optam por especializar as goleiras e jogadoras de quadra em categorias diferentes, possibilita a reflexão sobre os procedimentos pedagógicos adotados em cada categoria (aspecto não investigado nesta pesquisa), sobre os métodos de ensino preponderantes a cada categoria (a exemplo dos apontamentos de Menezes, 2018) e, consequentemente, a compreensão de como esse processo se dá em longo prazo. 


\section{Santos, W. R., Menezes, R. P.}

Embora neste estudo tenham sido bem definidos os aspectos para as categorias relacionadas à especialização de jogadoras de handebol, na prática tal processo pode não representar os achados. Uma das possibilidades se refere às condições para a manutenção da prática pelas jogadoras em longo prazo, intimamente ligada à estrutura das equipes para custear as despesas (muitas vezes de jogadoras com situação socioeconômica desfavorável), que abandonam o esporte para ajudar no custeio das despesas familiares. Ademais, não é possível ignorar a influência dos aspectos sociais e culturais ao longo do processo de especialização esportiva, os quais não foram investigados neste estudo.

\section{APLICAÇÕES PRÁTICAS}

Este estudo buscou compreender o momento considerado adequado para especializar jogadoras de handebol em postos específicos da modalidade, pautando-se na opinião de treinadores. A partir das entrevistas foi possível identificar as categorias consideradas mais adequadas para a especialização das goleiras (sub-16) e das jogadoras de quadra (sub18), que não coincidem pelas especificidades do posto específico (no caso das goleiras) e da necessidade de adaptações aos diferentes cenários do jogo (para as jogadoras de quadra). Foi possível observar, ainda, as justificativas que sustentam as diferenças mencionadas.

Destaca-se, ainda, que a opinião dos treinadores permitiu identificar tais aspectos partindose das suas experiências com equipes de todas as categorias, o que confere uma importante visão da construção do processo de formação e especialização em longo prazo. Porém, apresenta-se como um dos fatores limitantes deste estudo o fato de estar pautado em treinadores de equipes femininas do Estado de São Paulo. A investigação com treinadores de equipes masculinas pode revelar outro panorama, ao passo que outras perspectivas também podem ser identificadas a partir de entrevistas com treinadores de diferentes Estados e/ou âmbitos competitivos.

Os achados deste estudo, elucidados a partir dos discursos dos treinadores, se configuram como importantes balizadores para compreender e intervir ao longo do processo de formação e de especialização de jogadoras de handebol. Pelas categorias identificadas e suas respectivas características, esperase que ao ingressarem na categoria sub-16 as jogadoras tenham passado por um amplo processo de vivência no handebol que possibilite a especialização como goleira (também de acordo com suas preferências pessoais) e a continuidade do desenvolvimento de diferentes competências que permitirão, na categoria sub-18, a especialização das jogadoras de quadra. Esta especialização não se refere a limitar a atuação das jogadoras em apenas um posto específico, mas que as possibilite compreender o jogo em sua plenitude, solucionar situações-problema inerentes à dinâmica do jogo e, consequentemente, apresentar flexibilidade no comportamento técnicotático.

De modo complementar, os achados deste estudo (salvo as limitações do estudo ora apresentadas) proporcionam reflexões sobre a formação das jogadoras como um processo de longo prazo para o estabelecimento de possíveis diretrizes para os procedimentos pedagógicos adotados pelos treinadores, cujos resultados competitivos devam ser priorizados e valorizados apenas em categorias próximas à especialização.

Cabe aos treinadores, portanto, o planejamento e o desenvolvimento de um processo de ensino em longo prazo no handebol que aborde a complexidade do jogo por meio de diferentes métodos de ensino, a fim de desenvolver competências gerais e específicas que culminem em um processo paulatino de especialização.

Como perspectivas futuras aponta-se a possibilidade de ampliar o debate sobre a especialização no handebol, aprofundando-se nos motivos pelos quais os treinadores optam pela especialização em seu contexto específico de trabalho. Tais possibilidades ampliarão as reflexões sobre o processo de ensino-aprendizagem do handebol em longo prazo.

\section{REFERÊNCIAS}

1. Acero Gómez, R. (2007). Elentrenamiento del porteiro de balonmano em las etapas de iniciación. Revista de Ciencias Del Deporte, 3(10), 21-32.

2. Anguera, M. T., Blanco-Villaseñor, A., Hernández-Mendo, A. \& Losada, J. L. (2011). Diseños observacionales: ajuste y aplicación en psicología del deporte. Cuadernos de Psicología del Deporte, 11(2), 63-76. 


\section{Discursos de treinadores e especialização de jogadoras de handebol}

3. Anguera, M. T. \& Hernández-Mendo, A. H. (2013). La metodología observacional en el ámbito del deporte. E-balonmano.com: Revista de Ciencias del Deporte, 9(3), 135-160.

4. Anguera, M.T., Portell, M., Chacón-Moscoso, S. \& Sanduvete-Chaves, S. (2018). Indirect observation in everyday contexts: concepts and methodological guidelines within a mixed methods framework. Frontiers in Psychology, 19(3), 1-20. doi: 10.3389/fpsyg.2018.00013

5. Antón García, J.L. (2000). Balonmano: perfeccionamiento e investigación. Barcelona: INDE Publicaciones, 2000.

6. Ato, M., López, J. J. \& Benavente, A. (2013). Un sistema de clasificación de los diseños de investigación en psicología. Anales de Psicología, 29(3), doi:10.6018/analesps.29.3.178511

7. Baker, J.; Côtè, J. \& Abernethy, B. (2003). Sportspecific practice and the development of expert decision-making in team ball sports. Journal of Applied Sport Psychology. 15(1), 12-25. doi: 10.1080/10413200305400

8. Barreiros, A.; Côté, J. \& Fonseca, A.M. (2013). Sobre o Desenvolvimento do Talento no Desporto: Um Contributo dos Modelos Teóricos do Desenvolvimento Desportivo. Revista de Psicología del Deporte, 22(2), 489-494.

9. Canciglieri, P.H.; Melari, L.F. \& Pinheiro, P.U. (2008). Handebol: processo pedagógico e a especialização precoce. Revista Mackenzie de Educação Física e Esporte, 7(3), 79-82.

10. Carraça, B., Serpa, S., Palmi, J., \& Rosado, A. (2018). Enhance Sport Performance of Elite Athletes: The Mindfulness-Based Interventions. Cuadernos de Psicología del Deporte, 18(2), 79109

11. Corrêa, U. C.; Davids, K.; Silva, S.L.; Danardi, R.A. \& Tani, G. (2014). The influence of a goalkeeper as an outfield player on defensive subsystems in futsal. Advances in Physical Education, $\quad 4(2), \quad 1-9 . \quad$ doi: 10.4236/ape.2014.42012

12. Côtè, J.; Baker, J. \& Abernethy, B. (2007). Practice and play in the development of sport expertise. In: Tenenbaum, G.; Eklund, R.C.
Handbook of Sport Psychology. Hoboken: Wiley. 3 (8), 184-202.

13. Crusoé, N.M.C. (2004). A Teoria das Representações Sociais em Moscovici e sua importância para a pesquisa em educação. Aprender: Caderno de Filosofia e Psicologia da Educação, Ano II, n.2, p.105-114, 2004.

14. Ehret, A.; Spate, D.; Schubert, R. \& Roth, K. (2002). Manual de handebol: treinamento de base para crianças e adolescentes. São Paulo: Phorte.

15. Flick, U. (2009). Introdução à Pesquisa Qualitativa (Artmed Editora S.A. ed. Vol. 3).

16. Greco, P.J. \& Benda, R.N. (2002). O sistema de formação e treinamento esportivo do goleiro de handebol. In: Greco, P.J. (org.) Caderno do goleiro de handebol. Belo Horizonte: Impressão, 27-41.

17. Greco, P.J.; Silva, S.A. \& Greco, F.L. (2012). O sistema de formação e treinamento esportivo no handebol brasileiro (SFTE-HB). In: Greco, P.J.; Fernández Romero, J.J. (Orgs.). Manual de handebol: da iniciação ao alto nível. São Paulo: Phorte, 230-250.

18. Guimarães, G.L; Mourão, L.; Oliveira, A.P. \& Santos, R.F. (2009). Treinamento de equipes mirins e infantis femininas: a concepção dos treinadores de voleibol do estado do Rio de Janeiro. Pensar a Prática, 12(1), 1-11. doi: 10.5216/rpp.v12i1.5571

19. Hernandes, R.M.; Ferronato, P.A.M. \& Fraga, C.H.W. (2015). Especialização precoce em praticantes de handebol. Journal of Health Science Institute. 33(4), 376-382.

20. Latiskevits, L.A. (1991). Balonmano: deporte \& entrenamiento. Barcelona: Editorial Paidotribo

21. Lefèvre, F. \& Lefèvre, A.M.C. (2012). Pesquisa de representação social: um enfoque qualiquantitativo. 2.ed. Brasília: Liber Livro Editora.

22. Malina, R.M. Marion; Bouchard, C. \& Bar-Or, O. (2009). Crescimento, maturação e atividade física. 3.ed. São Paulo: Phorte.

23. Marconi, M.A. \& Lakatos, E.M. (2011). Metodologia do trabalho científico: procedimentos básicos, pesquisa bibliográfica e 


\section{Santos, W. R., Menezes, R. P.}

relatório, publicações e trabalhos científicos. 6.ed. São Paulo: Atlas.

24. Massuça; L. \& Fragoso, I. (2010). Do talento ao alto rendimento: indicadores de acesso à excelência no handebol. Revista Brasileira de Educação Física e Esporte, 24 (4), 483-491. doi: 10.1590/S1807-55092010000400006

25. Massa, M.; Uezu, R.; Böhme, M. T. S.; Silva, L. R. R. \& Knijnik, D. (2010). Desempenho esportivo no judô olímpico brasileiro: o talento é precoce? Revista Brasileira de Ciência e Movimento, 18 (1), 5-10. doi: 10.18511/rbcm.v18i1.1151

26. Menezes, R. P. (2010). O ensino dos sistemas defensivos do handebol: considerações metodológicas acerca da categoria cadete. Pensar a Prática. $13 \quad$ (1), 1-15. doi: 10.5216/rpp.v13i1.7269

27. Menezes, R. P. (2011). Modelo de análise técnicotática do jogo de handebol: necessidades perspectivas e implicações de um modelo de interpretação das situações de jogo em tempo real. (Doutorado), Universidade Estadual de Campinas, Campinas.

28. Menezes, R. P. (2012). Contribuições da concepção dos fenômenos complexos para o ensino dos esportes coletivos. Motriz. 18 (1), 3441. doi: 10.1590/S1980-65742012000100004

29. Menezes, R. P. (2018). Ensino do handebol em longo prazo: estudo a partir da opinião de treinadores. Educación Física y Ciencia, 20(2), e048. doi:10.24215/1514-0105e048

30. Menezes, R. P.; Marques, R. F. R. \& Nunomura, M. (2014). Especialização esportiva precoce e o ensino dos jogos coletivos de invasão. Movimento. 20 (1), 351-373. doi: 10.22456/1982-8918.40200

31. Menezes, R. P., Marques, R. F. R. \& Nunomura, M. (2015). O ensino do handebol na categoria infantil a partir dos discursos de treinadores experientes. Movimento, 21(2), 463-477. doi: 10.22456/1982-8918.47664

32. Menezes, R. P., Marques, R. F. R. \& Nunomura, M. (2017). Teaching handball to players under-12: the perspective of Brazilian coaches. Motriz, 23(4), e101792. doi: 10.1590/s19806574201700040006
33. Menezes, R. P.; Reis, H. H. B. \& Tourinho Filho, H. (2015). Ensino-aprendizagem-treinamento dos elementos técnico-táticos defensivos individuais do handebol nas categorias infantil, cadete e juvenil. Movimento. 21(1), 261-274. doi: 10.22456/1982-8918.46159

34. Milistetd, M.; Mesquita, I.; Nascimento, J. V. \& Sousa Sobrinho, A. E. P. (2010). Concepções de treinadores "experts" brasileiros sobre o processo de formação desportiva do jogador de voleibol. Revista Brasileira de Educação Física e Esporte. 24 (1), 79-93. doi: 10.1590/S180755092010000100008

35. Modolo, F. \& Menezes, R. P. (2019). Características técnico-táticas dos goleiros de handebol da categoria sub-16: opinião de treinadores brasileiros. Cuadernos de Psicología del Deporte. 19(1), 206-221.

36. Morelló Tomás, E.; Vert Boyer, B.; Navarro Barquero, S. (2018). Establecimiento de objetivos en el currículum formativo de los futbolistas. Revista de Psicología Aplicada al Deporte y al Ejercicio Físico, 3(e3), 1-9. doi: 10.5093/rpadef2018a7

37. Oliver, D., Serovich, J. \& Mason, T. (2005). Constraints and opportunities with interview transcription: Towards reflection in qualitative research. Social Forces, 84(2), 1273-1289. doi: 10.1353/sof.2006.0023

38. Sainz de Baranda, P.; Ortega, E. \& Palao, J. M. (2008). Analysis of goalkeepers' defence in the World Cup in Korea and Japan in 2002. European Journal of Sport Science. 8 (3), 127-134. doi: 10.1080/17461390801919045

39. Silva, A. S.; Fonseca A. M.; Barreiros, A. (2019). Exploring the importance of coaches in the development of the sports career in Handball. The perception of athletes from higher and lower levels of success. Cuadernos de Psicología del Deporte, 19(1), 106-120

40. Thomas, J. R.; Nelson, J. K. \& Silverman, S. J. (2012). Métodos de pesquisa em atividade física. Artmed: Porto Alegre.

41. Triviños, A. N. S. (1987). Introdução à pesquisa em ciências sociais: a pesquisa qualitativa em educação. São Paulo: Atlas. 
Discursos de treinadores e especialização de jogadoras de handebol

42. Wright, C., Carling, C., Lawlor, C. \& Collins, D. (2016). Elite football player engagement with performance analysis. International Journal of Performance Analysis in Sport, 16(3), 1007-1032. doi: 10.1080/24748668.2016.11868945 